\title{
THE FACTORS WHICH AFFECT THE ENERGY LOSSES IN ARMATURE CORES.
}

\section{J. WALTER ESTERLINE AND C. E. REID.}

The investigations which form the basis of this paper have been conducted at the Electrical Laboratory of Purdue University during the past two years. The purpose was primarily to develop an apparatus suitable for rapid yet accurate testing of sheet metal used in armature cores; secondary to this was the study of the effect of certain factors upon the energy losses which occur in the armature cores of generators and motors.

\section{The Apparatus.}

A general view of the apparatus is given in Fig. 1. The wrought iron field-ring is 14 inches in diameter, 3 inches in width, with an inner diameter of $10 \frac{3}{8}$ inches. This yoke is provided with five sets of poles, as follows: (1) 2 poles, solid wrought-iron;(2), 4 poles, solid wrought iron; (3), 6 poles, solid wrought iron; (4), 8 poles, solid wrought iron; (5), 2 poles, built of .022 sheet steel. The poles are so dimensioned that $50 \%$ of the armature core is covered by each set. The field poles and exciting coils are shown in Fig. 2.

The apparatus was designed so that the specimens for test would be in the form of ordinary armature punchings, and the samples tested consisted of seven cores built up of sheet steel discs .015 inches thick. Fig. 3 is from a photograph of dises from the different cores. The outer diameter of these is six inches, while the inner diameters vary from 2 to 5 inches, in different cores. Four of the specimens tested have a smooth periphery, and three others, with corresponding inner diameters, are slotted. The slots in these cores are 48 in number and $3 / 16$ inches wide by $\frac{1}{2}$ inch deep. 


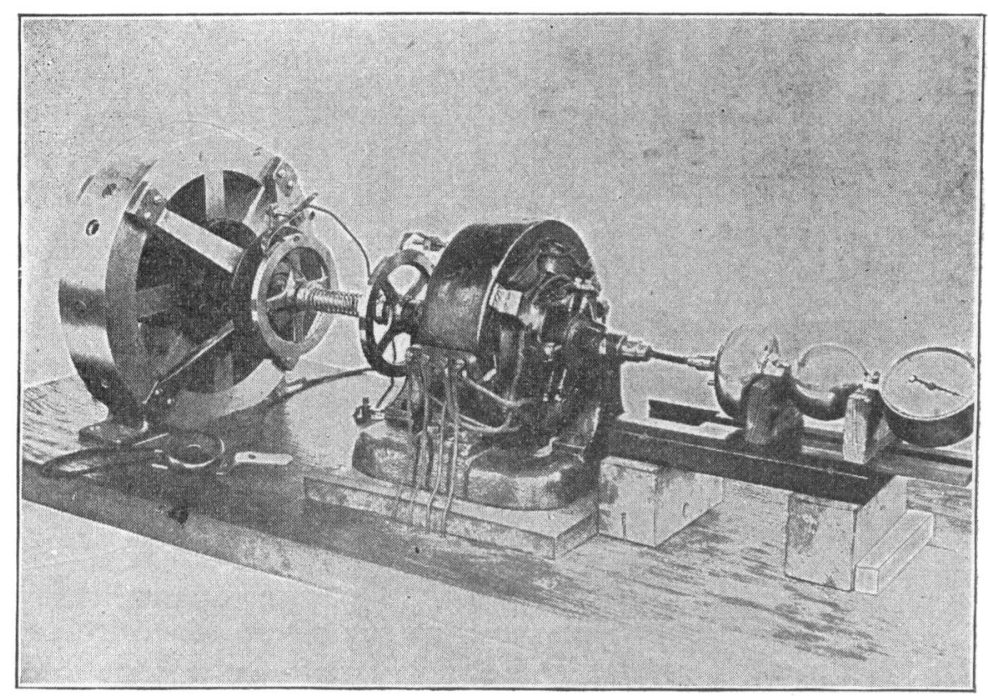

FIG. 1.

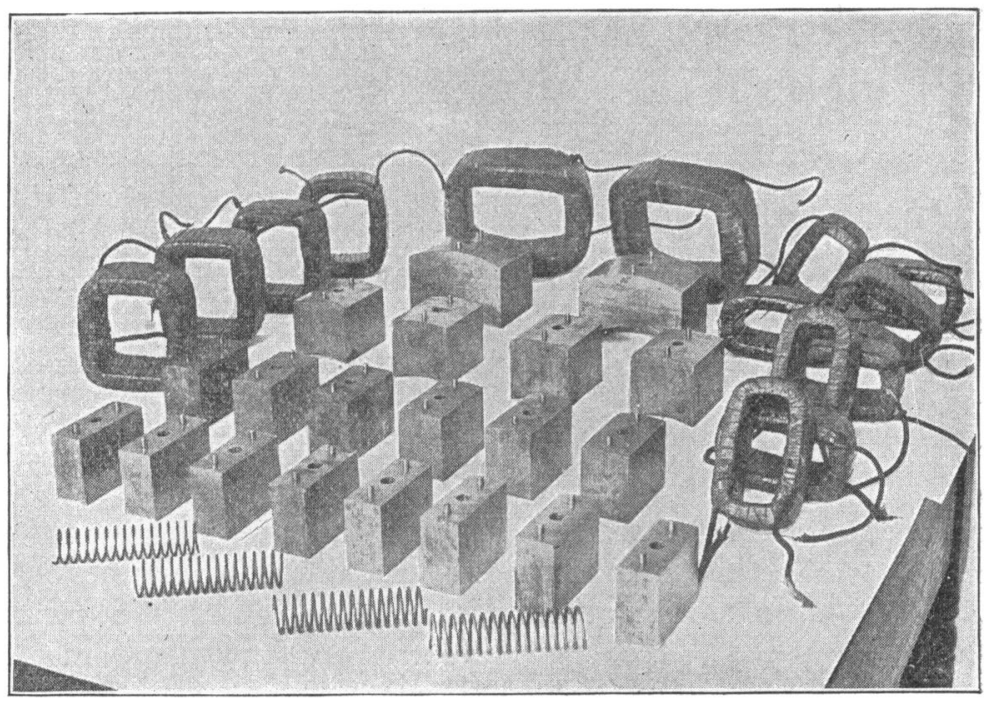

FIG. 2. 
To insure a uniform quality of metal in all the cores, the discs were all stamped and then thoroughly shuffled, after which the holes were punched in the different lots. The slots were milled in the cores which were to be toothed, and all the discs were carefully annealed.

The punchings were given a coat of shellac and mounted on hardwood sleeves which fit a heavy steel shaft carried in bearings fastened directly to the field-ring.

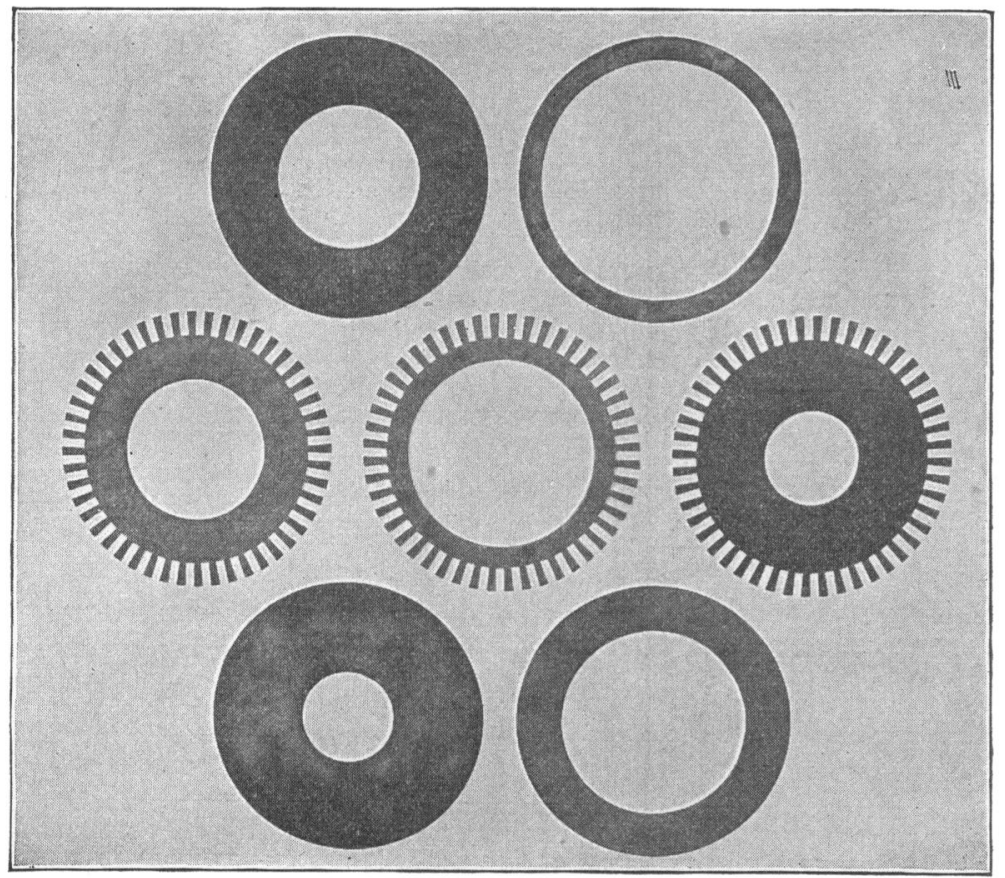

FIG. 3.

In order to insure a uniform density in the air gaps under the different poles, so that there would be no undue increase in the bearing friction when the fields are excited, and to insure an equal distribution of the flux in the core, the poles were bored while clamped in the field ring, the tool being carried on the s'raft.

The shaft was driven by a small direct current motor through a modified form of the Goldsborough torsion dynamometer shown in Fig. 4.* The bearings which formed a part of the

*Trans. A. I. E. E., 1900. 
original type of dynamometer were discarded, one of the wheels was carried on the driving-end of the motor shaft and the driven member fitted to a quill which fits the shaft of the apparatus, permitting the removal of the latter without disturbing the adjustment of the dynamometer spring. The dynamometer was adjusted to the desired degree of sensitiveness by changing the size of spring used.

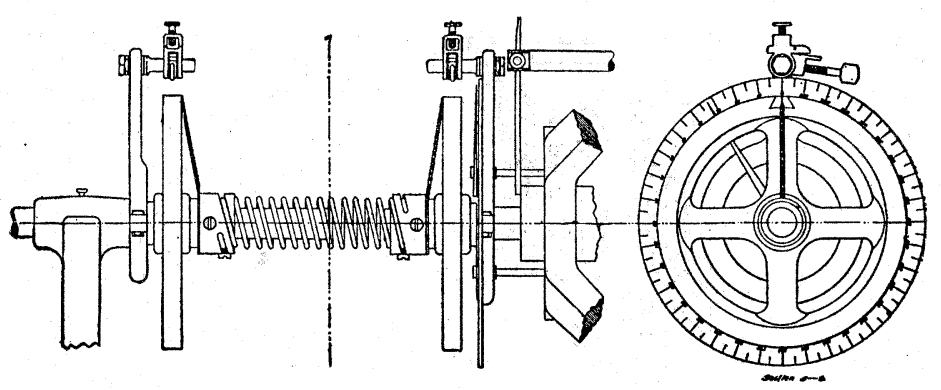

FiG. 4.-Dynamometer Detalls.

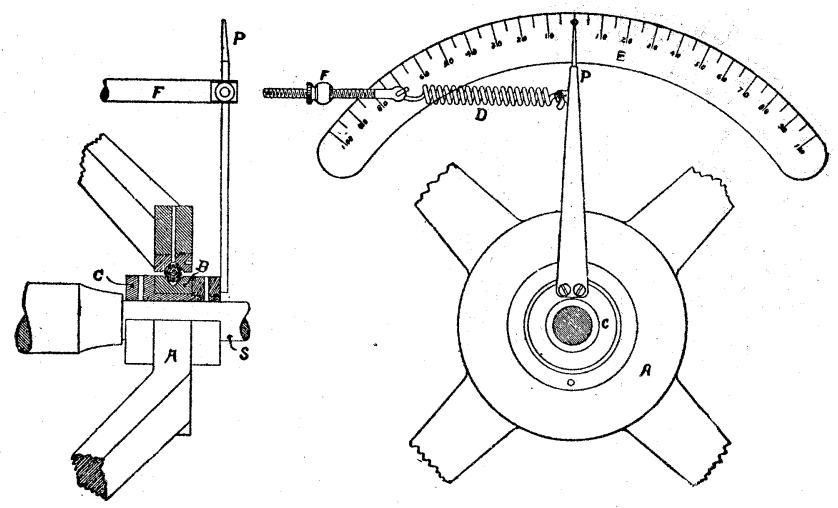

FIG. 5.-Bearing Details.

In order to detect and correct for any change of the bearing friction, should the armature become magnetically unbalanced, or the lubrication of the bearings imperfect, the bearings were made of special design, as shown in Fig. 5. The shaft runs in the phoshpor-bronze bearing $\mathrm{c}$, which, instead of being fastened firmly to the arm $\mathrm{A}$, is mounted in a ball bearing $\mathrm{B}$. When the shaft is rotating, the friction tends to cause the bearing $\mathrm{c}$ to 
rotate with the shaft, as the friction of the ball-bearing was found by test to be negligible in comparison with that of the plain bearing. Instead of allowing $\mathrm{c}$ to rotate, it is held by a spring $\mathrm{D}$ attached to an arm at $P$. At the beginning of a run the adjustment at $F$ was made such that the pointer stood at $o$ when the machine was running at the speed at which the test was to be run. Any increase in the friction of the bearings is measured by the movement of $\mathrm{P}$ in the direction of rotation, and the reverse for any decrease. The divisions on the scale $\mathrm{E}$ represent the number of degrees through which it is necessary to twist the dynamometer spring to produce the given deflection of the spring $\mathrm{D}$, i.e., 10 divisions on the scale $\mathrm{E}$ indicate that if the torque necessary to twist the dynamometer spring through 10 degrees be applied to the spring D, the pointer will indicate 10. Such a scale was calibrated for each of the two bearings for each of the dynamometer springs used, by clamping the bearing $\mathrm{c}$ to the shaft, and marking the position of $\mathrm{P}$ corresponding to the different angles through which the dynamometer spring was twisted in order to produce the deflection of $\mathrm{D}$.

The driving-motor was operated separately-excited, and variable speed was obtained by changing the impressed e.m.f. of the armature. The speed was indicated by a Buss-Sombart tachometer attached to the armature shaft of the motor.

\section{Purpose and Method of Tests.}

The energy losses which attend the rotation of an armature core in the magnetic field consist of the bearing-friction and windage, hysteretic and eddy current loss in the core in the case of smooth cores, to which is added an eddy current loss in the pole faces when the cores are toothed.

As indicated in the following diagram, the hysteretic losses may be said to depend upon the quality of the iron, the frequency of the flux reversals and the maximum density reached during a cycle. The frequency is a function of the number of poles and the speed. The maximum magnetic density is dependent upon a number of conditions, and is usually different in different parts of the core at the same instant. The distribution of the magnetic flux through the core depends mainly upon the depth of the core, the number and pitch of the poles and the dimensions of the tooth and slot. The greater the radial depth of the core, the greater the difference between the maximum and minimum densities within the core, for a given average density, and as the depth of the core becomes less the distribution of the flux becomes more 
and more uniform. The cores of different internal diameters were tested to determine the effect of the variation in the flux distribution upon the core loss. The frequency and flux distribution both being dependent upon the number of poles in a machine, these cores were tested under different numbers of poles also.

When an armature core is slotted, the magnetic density in the teeth is greatly increased for a given air gap or core density, and the presence of teeth on the core is attended by an eddy current loss in the poles. The latter may be greatly reduced by laminating the poles, so that a comparison between tests of a toothed core under solid and laminated cores should indicate to what extent this loss in the pole faces may be reduced. The increase in the energy expended due to the higher densities in the teeth may be shown by comparing tests of smooth and toothed cores under well laminated poles.

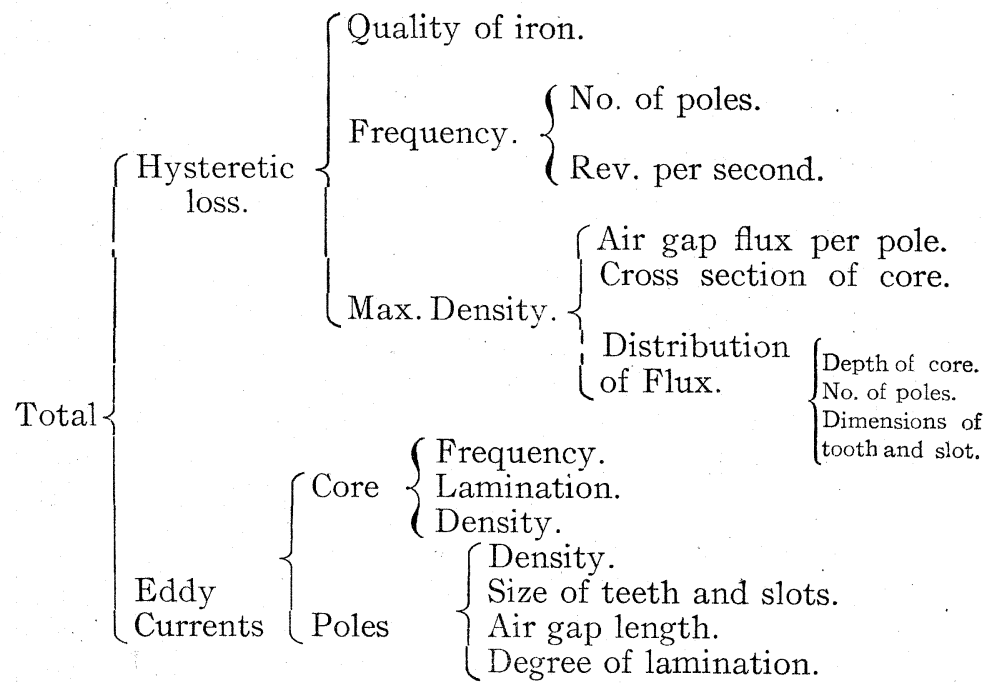

To make a core, enough discs of one kind were selected to give a gross length of 3 inches. These were weighed, given a coat of shellac and assembled. Before placing the core within the field an exploring coil was wound about the face of one of the poles and another wound so as to embrace the total flux passing through one section of the core. After placing the sample in the apparatus, a saturation curve was taken by means of a ballistic galvanometer in connection with the exploring coils just mentioned. These curves (Fig. 6) show the relation between ampere-turns per pole and average magnetic density in the core. 
The field poles were next thoroughly demagnetized by an alternating current. On starting the motor, the dynamometer reading indicates the bearing friction and windage, the springs which hold the bearings were adjusted so that the reading of the pointers $\mathrm{P}$, was zero.

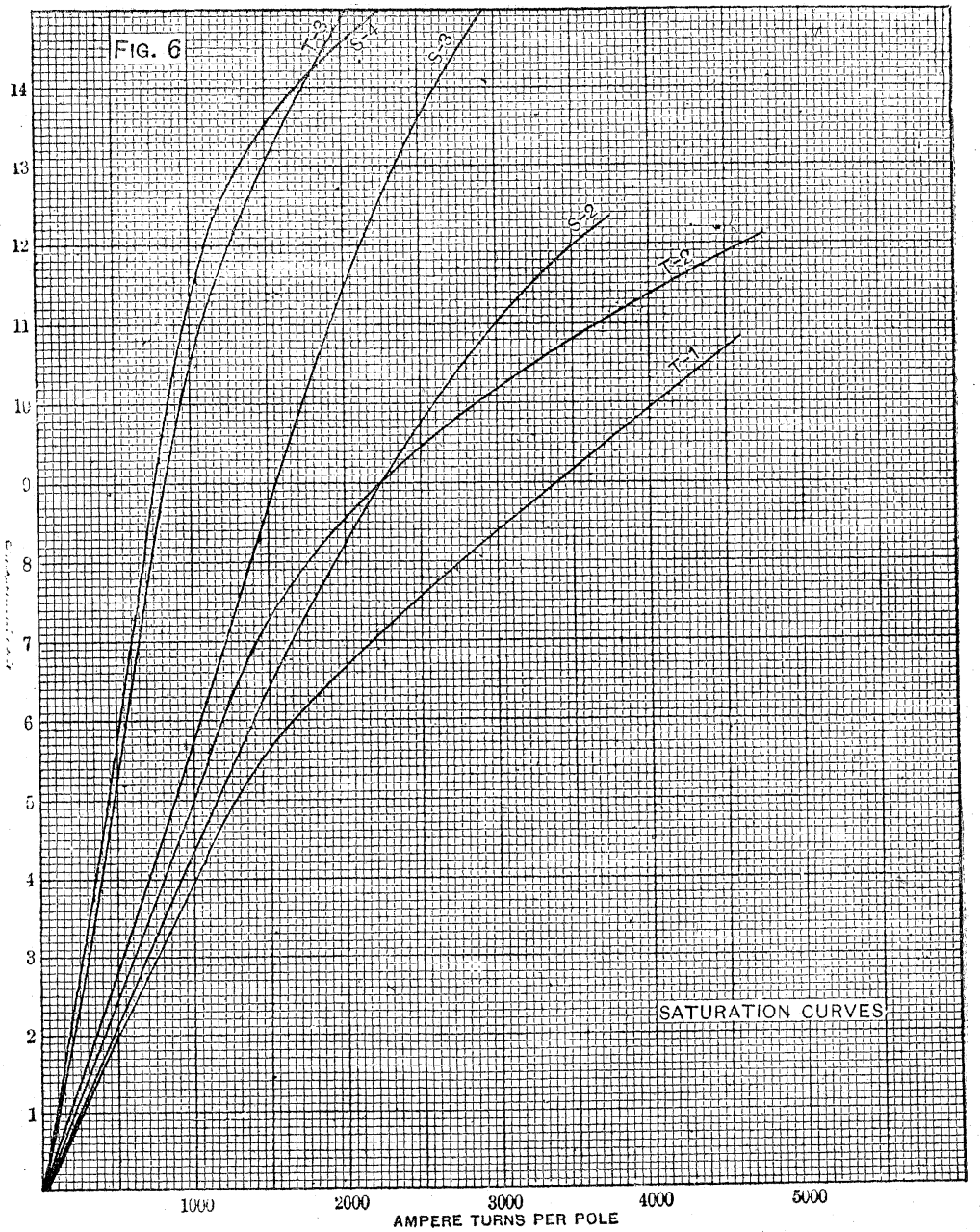

The speed being adjusted to give a desired frequency, it was held constant, and the exciting current varied stepwise, readings of current in the fields, dynamometer and scale for bearing friction, being taken simultaneously for each value of current. When maximum current was reached, the fields were again demag- 
netized, the speed changed to give the next desired frequency, the bearing springs adjusted and the operation of varying the current repeated. Each core was tested in this manner under five sets of poles, at five different frequencies and varying magnetic densities, making 225 complete tests.

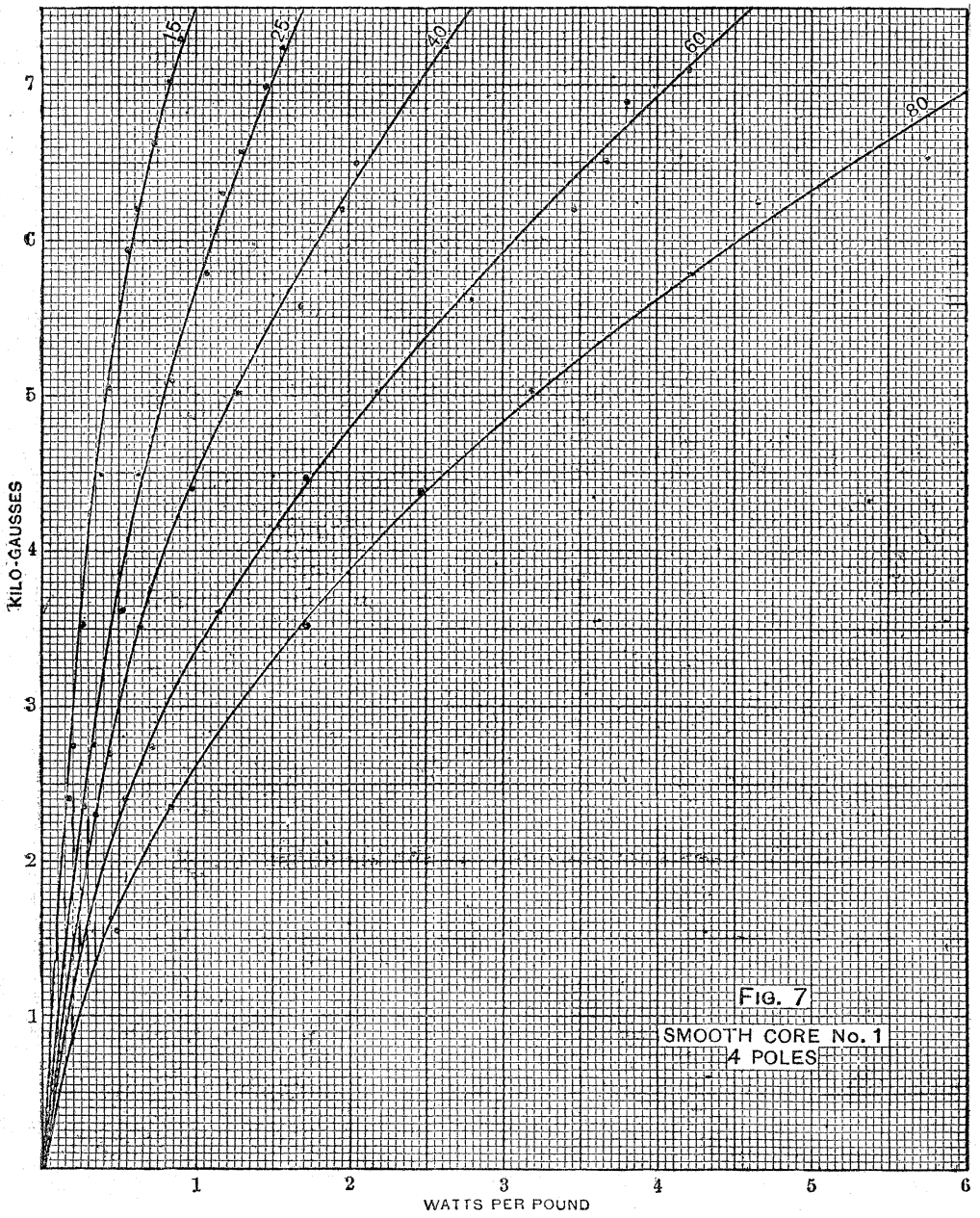

When the fields are excited, the power required to drive the core consists of the friction and windage and iron losses. The difference between the dynamometer reading for any current, and the friction reading, is the iron loss. If the pointers attached to the bearings indicate any change in the friction, the amount so indicated can be subtracted from or added to the original 
friction reading, depending upon whether the friction has decreased or increased, since the scales $\mathrm{E}$ are graduated in degrees of the dynamometer spring. From the corrected dynamometer readings the watts core-loss in watts was determined, which divided by the weight of the core gives the watts per pound. Referring to the saturation curve, the densities in the core for

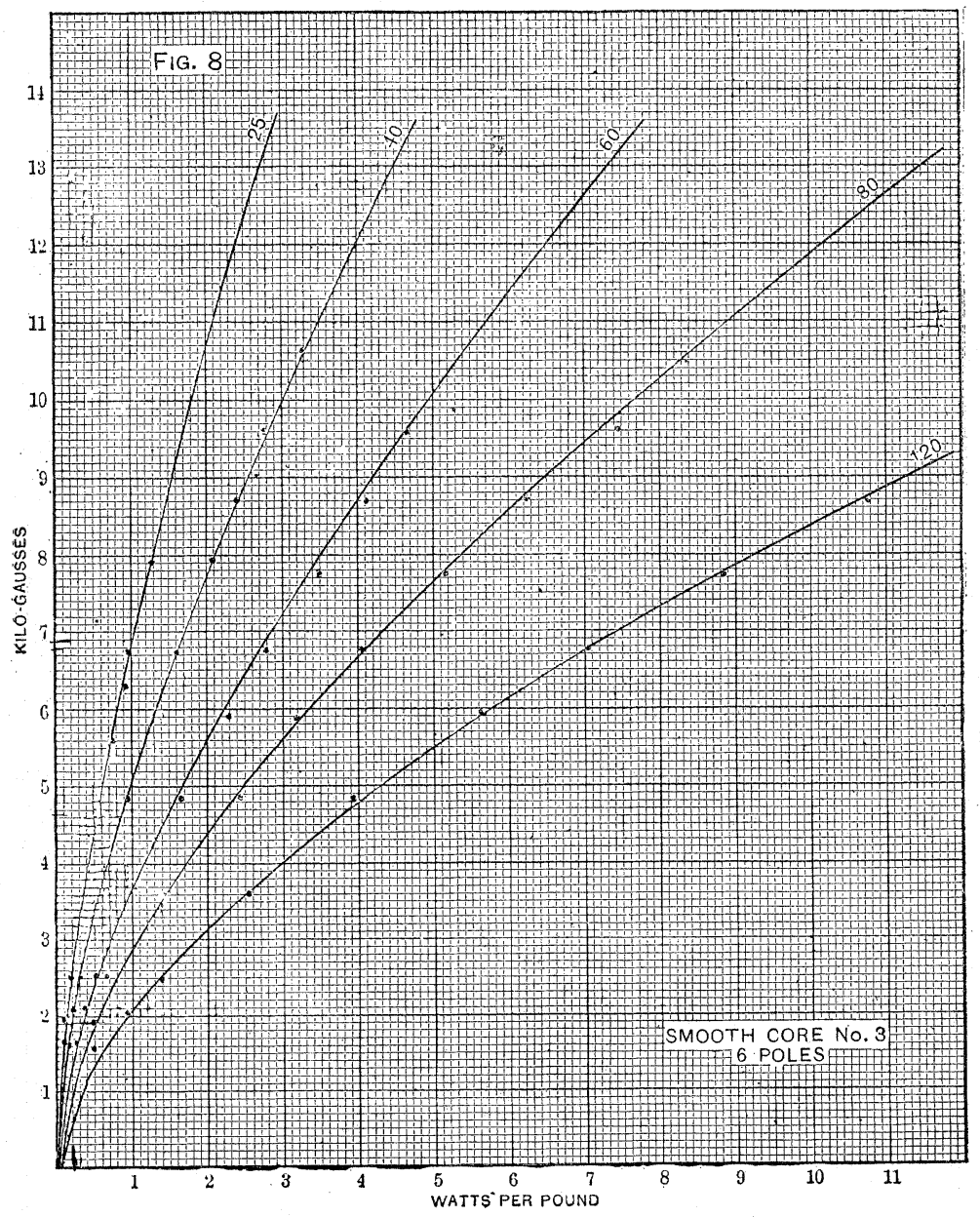

the different values of ampere-turns per pole are found, and curves plotted for each frequency, average density as ordinates, watts per pound abscissæ. The original curves from 2 of the 35 tests are shown in Figs. 7 and 8. The current in the exciting coils was taken from a storage battery and measured by a 
Weston laboratory standard ammeter. The dynamometer was frequently calibrated, and gave the same result each time. The centering of the cores in the bore of the poles was so successfully accomplished, that there was very little increase in the friction due to magnetic pull. So sensitive, however, were the ball bearing attachments, that the increase of friction due to a drop of cold oil in one of the bearings was readily shown by the pointer.

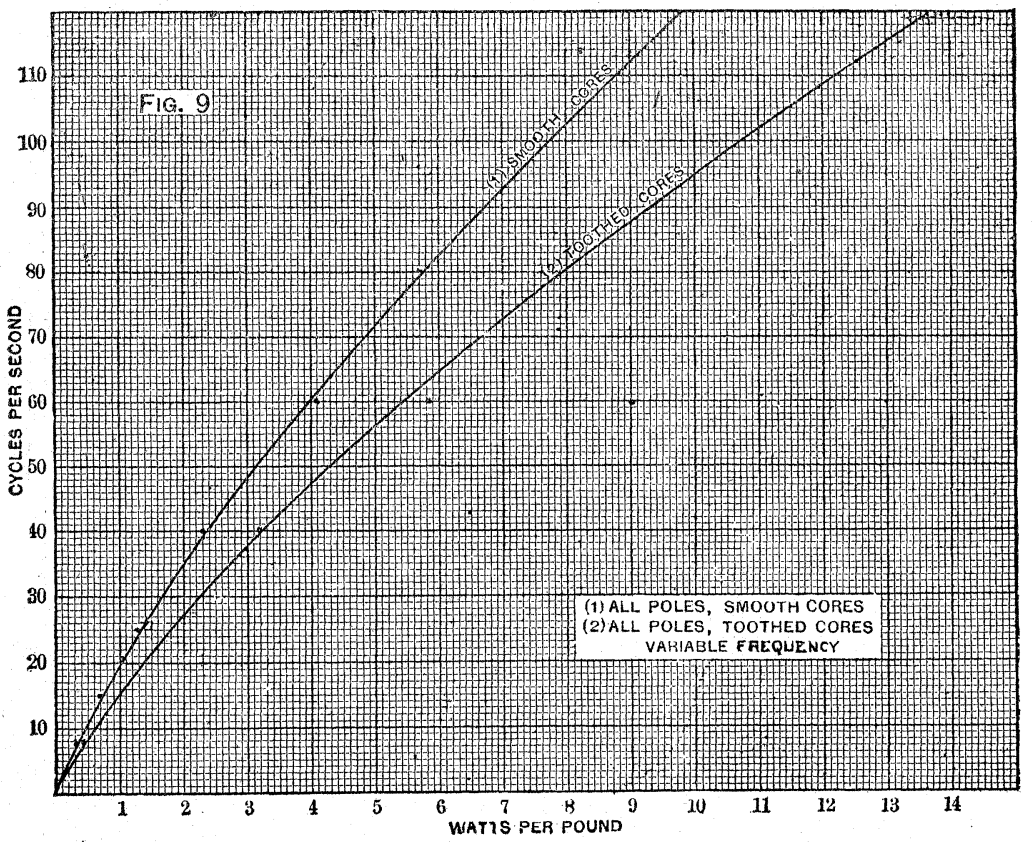

Results.

To illustrate the relation between the core loss and any one of the four variables - frequency, magnetic density, number of poles and depth of core-curves have been drawn from data derived from the 35 original curves. In order that the results should be representative, the three variable factors not under consideration were eliminated by averaging all of the tests, for each value of the variable under consideration. For example, Curve N . 1, Fig. 9, exhibits the relation between the frequency in cycles per second and core loss in watts per pound, for all the cores having smooth periphery, under sets of $2,4,6$ and 8 poles, and at magnetic densities ranging from 2,000 to 14,000 gausses, for each value of frequency. 
Curve No. 2 , in the same figure, shows a similar relation for all of the toothed cores. The curve for the cores having teett, shows considerably higher losses, due to the energy loss in the pole faces and the increased hysteresis loss resulting from the high magnetic density in the teeth of the core.

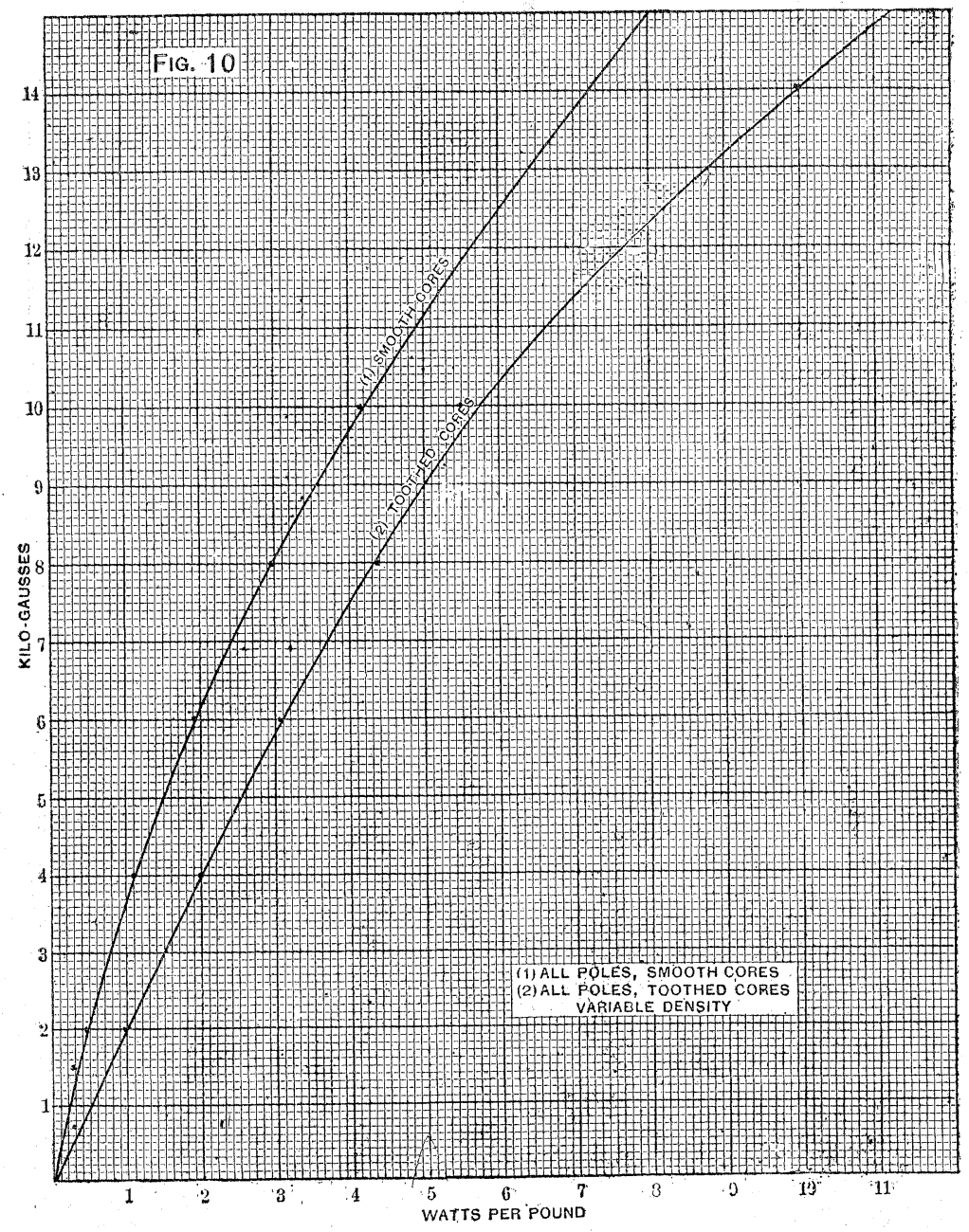

Curve No. 1, Fig. 10, gives the relative values of the core loss and maximum average magnetic density for all of the smooth core at frequencies ranging from 7.5 to 120 cycles persecond. Curve No. 2 shows a similar relation for the toothed cores.

In studying the effect of variable numbers of poles and depth 

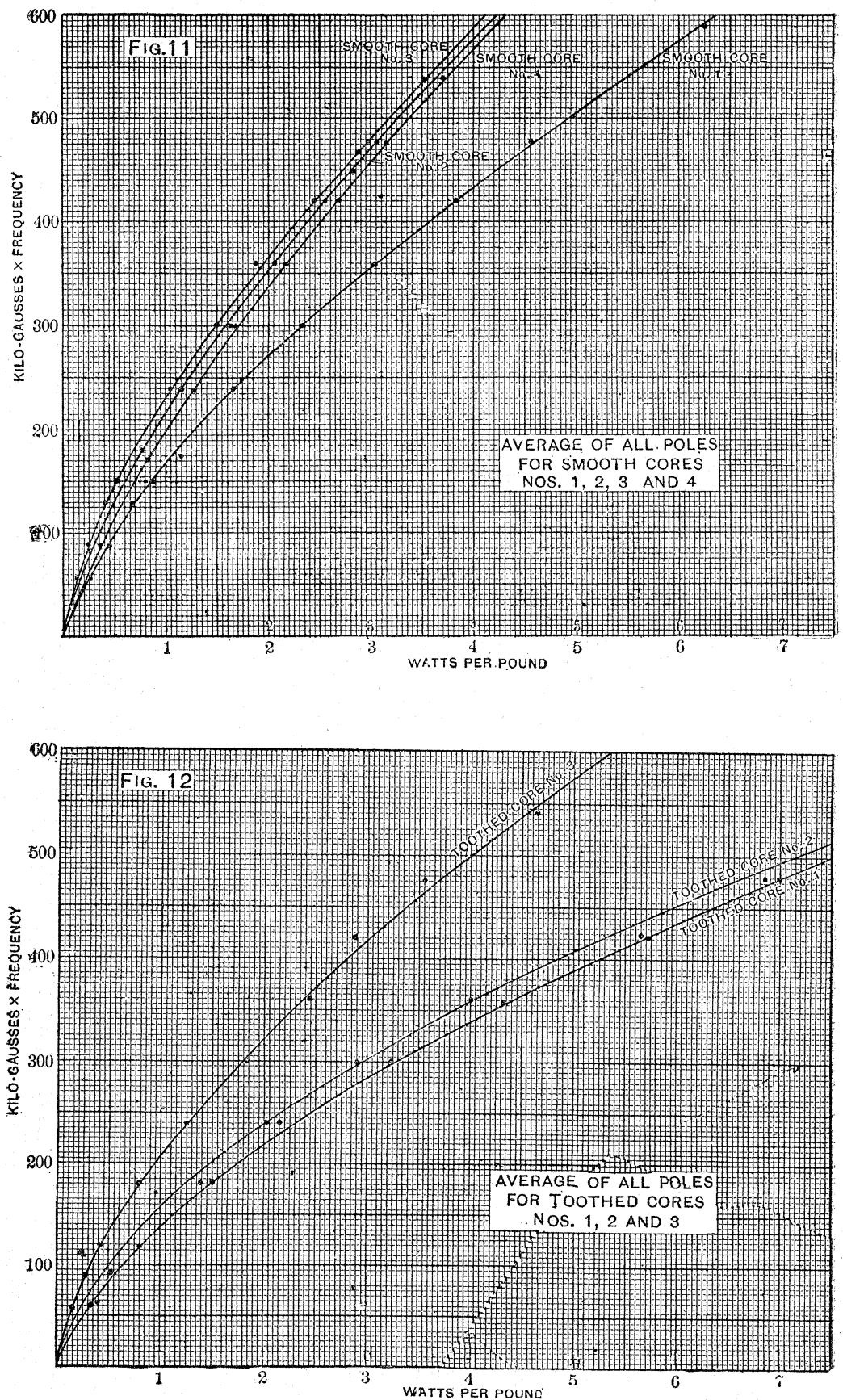
of core, the product of the frequency and magnetic density was considered as a single variable. As shown in Fig. 11, the relatively shallow cores, in which the magnetic density is more nearly uniform, have the lowest values of core-loss for the same average magnetic density and frequency. The same is true for the toothed cores, as shown in Fig. 12. The lines of force in passing from pole to pole through the core, seek the path of least reluctance, and in so doing increase the density in the outer portions of the core. In Fig. 11, core No. 1 has a radial depth of 2 inches, No. 2, 1.5 inches, No. 3, 1 inch, No. $4, .5$ inch. Of the

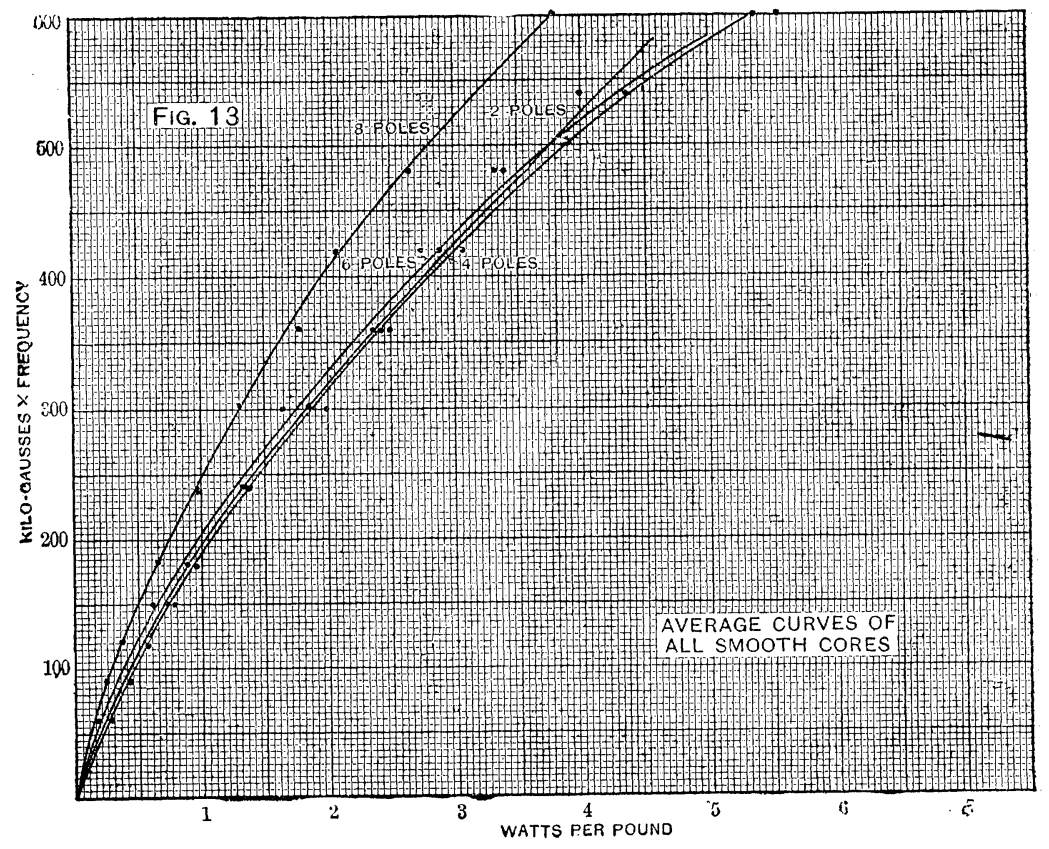

toothed cores, the results from which are given in Fig. 12, core No. 1 has a depth below the teeth of 1.5 inches, No. 2, 1 inch, and No. $3, .5$ inch.

Fig. 13 would indicate that there is practically little change in the core loss for different numbers of poles, for the same magnetic density and frequency, so far as the smooth cores are concerned. The curve for 8 poles differs from the other three on the same sheet, more probably due to the fact that it was impossible to obtain as high magnetic densities with these poles as with the others, but the frequencies obtained were of course somewhat. 

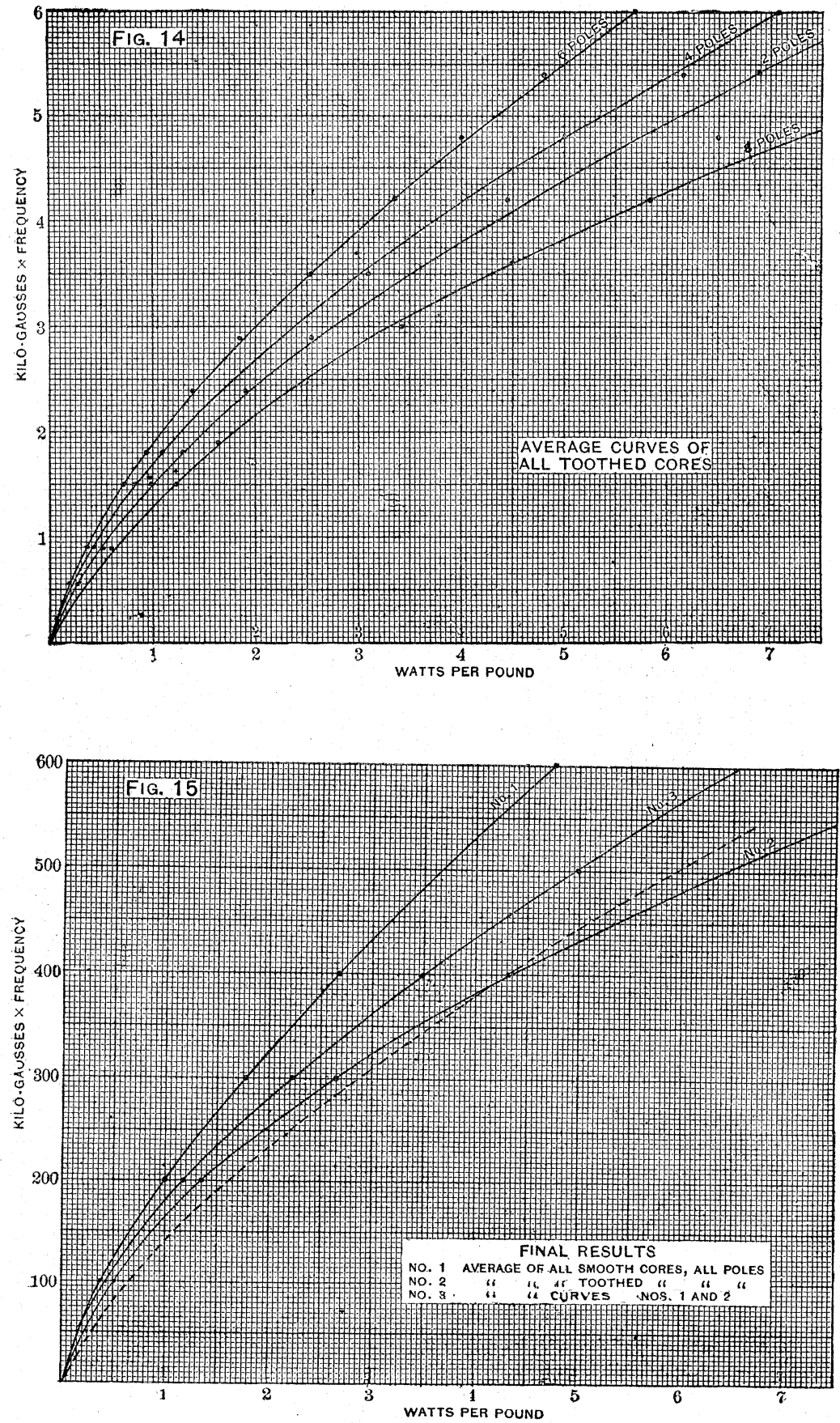
higher. However, in the case of the toothed cores, as shown in Fig. 14, there is considerable variation in the core loss for different sets of poles, at the same frequency and density.

In Fig. 15 curve No. 1 is the average of the four curves shown in Fig. 13, and therefore is a summation of all data taken on the cores having smooth periphery. Curve No. 2 in the same figure is a similar deduction from all the data on the slotted cores. The increase in the loss of energy due to the slotting of the core is plainly set out, as shown by the difference of the values of the abscissæ of the curves 1 and 2. Curve No. 3 is a final average of

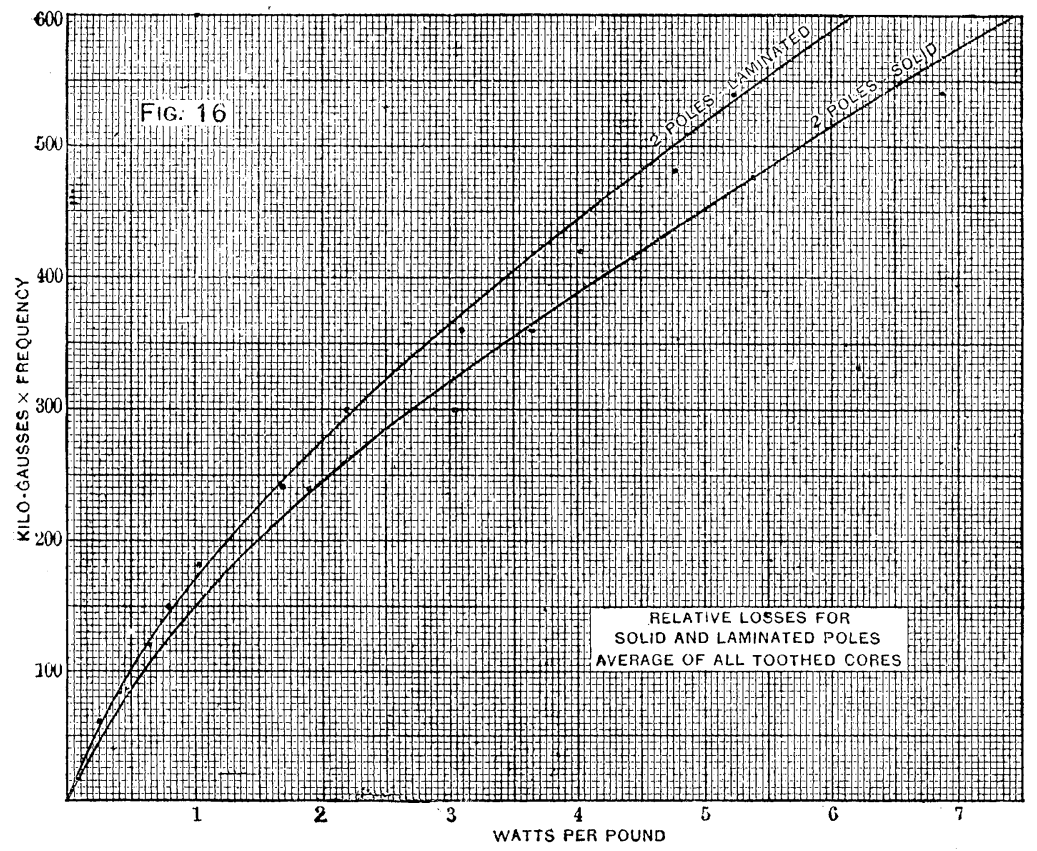

the results from all the smooth and all the toothed cores and is the result of some 12,000 observations.

Curve No. 1, Fig. 16, is the mean result of all the toothed cores tested under a pair of laminated poles, while Curve No. 2 in the same figure is the result of tests of the same cores under a pair of solid poles; the difference in the abscissæ of these two curves denoting the reduction of the eddy current loss in the poles due to lamination of the same. In building up the laminated poles, no effort was made to produce a laminated pole in any way superior to those obtained in commercial practice. After the poles were 
built up, they were faced inside and out, in the lathe; and the tests conducted on the poles just as they came from the lathe, no. attempt being made to remove the effects of the tool in forcing. the plates together.

It will be noted in curve No. 1, Fig. 16, the toothed cores. and laminated poles check fairly closely with curve No. 3 of Fig. 15, which is the average of the smooth and toothed cores. under solid poles, and also that the difference between curve 2 and 3 , Fig. 15 , is very nearly equal to the difference between the curves in Fig. 16. This being the case, we should expect curve No. 1, Fig. 15, to be representative for smooth cores under either solid or laminated poles; curve No. 3 for toothed cores, with laminated poles and curve No. 2 for toothed cores and solid poles. The broken curve (Fig. 15), is from the core loss tests of a large number of machines having, in the majority of cases, toothed cores and solid cast poles. Since these machines were built and tested by the manufacturing company which furnished the material for the cores which were the subject of these investigations, the last conclusion at least seems justifiable.

In conclusion the authors desire to express their obligations to Messrs. A. E. Wood and C. A. Davis, of the graduating class of 1902, for much assistance in preparing the apparatus and samples; to Messrs. R. E. Clisby, A. W. McHenry and J. W. Skinkle, class of 1903, Purdue University, for painstaking efforts in making the observations and calculating the results: also to Mr. A. L. Hadley for much valuable assistance. 